\title{
Gorham-Stout disease successfully treated with sirolimus (rapamycin): a case report and review of the literature
}

\author{
Yu Liang ${ }^{\dagger}$, Ruicheng Tian ${ }^{\dagger}$, Jing Wang, Yuhua Shan, Hongxiang Gao, Chenjie Xie, Jingjing Li, Min Xu and \\ Song $\mathrm{Gu}^{*}$
}

\begin{abstract}
Background: Gorham-Stout disease (GSD) is a rare disease characterized by bone lesions and osteolysis. Therapy usually involves surgical resection. Sirolimus (Rapamycin) is used in some patients with GSD but the efficacy and safety of Sirolimus remains unclear. We propose that Sirolimus may be a novel therapeutic for GSD and present a case and review of literature that supports this.

Case presentation: We presented a 1-year-old boy with GSD involving osteolysis of the right humerus with fracture of the left femur complicated by an effusion in the right pleural cavity. X-rays showed osteolysis in the right clavicle. A large pleural effusion was observed on the right-side, and the left lung was significantly compressed. Xrays also showed a fracture of the left femur. A femoral biopsy was performed that showed necrotic tissue in the cortical bone and a large number of irregularly shaped capillaries that proliferated within the necrotic tissue. Dilated lymphatic vessels were seen adjacent to the cortex, with fibrous tissue hyperplasia. We prescribed sirolimus, which is an oral mTOR inhibitor, for two consecutive years. The boy recovered well without other progressive bone lesions and participates in normal daily activities. His growth and development are the same as that of his peers.
\end{abstract}

Discussion and conclusion: Gorham-Stout disease is a rare and enigmatic disease characterized by the presentation of an intraosseous lymphatic anomaly $(L M)$, which results in progressive bone resorption. Based on this case report and a literature review, we conclude that sirolimus may be an effective alternative medication for GSD.

Keywords: Gorham-Stout disease, Osteolytic lesion, Sirolimus (rapamycin), Treatment

\section{Background}

Gorham-Stout Syndrome, also known as GSD, results in massive osteolysis and bone loss. The disease was first reported in 1838 [1] but was systematically described in 1955 by Gorham and Stout based on their clinical experience and the literature [2]. To date, about 300 cases have been reported worldwide. Commonly, GSD is defined as progressive bone resorption, which occurs either slowly or

\footnotetext{
* Correspondence: jackxm1236@126.com; gusong@shsmu.edu.cn

${ }^{\dagger}$ Yu Liang and Ruicheng Tian should be regarded as joint first authors. Department of Surgery, Shanghai Children's Medical Center, Shanghai Jiaotong University School of Medicine, Dongfang Road No.1678, Pudong District, Shanghai 200127, China
}

rapidly, in association with proliferation of lymphatics or blood vessels in areas adjacent to the osteolytic bone. The cause of the abnormal proliferation of vascular and lymphatic channels remains unknown, although there are different hypotheses about pathogenesis involving vascular endothelial growth factor or osteoclast hyperactivity. It occurs more often in children and can involve any bone. Current therapies include surgery, radiotherapy, and pharmaceuticals [3], but there is no consensus about treatment of this rare disease. Most recently, Tena ME et al. [4] reported two cases with GSD. One went into remission when biological reconstruction was performed on three

(c) The Author(s). 2020 Open Access This article is licensed under a Creative Commons Attribution 4.0 International License, which permits use, sharing, adaptation, distribution and reproduction in any medium or format, as long as you give appropriate credit to the original author(s) and the source, provide a link to the Creative Commons licence, and indicate if changes were made. The images or other third party material in this article are included in the article's Creative Commons licence, unless indicated otherwise in a credit line to the material. If material is not included in the article's Creative Commons licence and your intended use is not permitted by statutory regulation or exceeds the permitted use, you will need to obtain permission directly from the copyright holder. To view a copy of this licence, visit http://creativecommons.org/licenses/by/4.0/ The Creative Commons Public Domain Dedication waiver (http://creativecommons.org/publicdomain/zero/1.0/) applies to the data made available in this article, unless otherwise stated in a credit line to the data. 
occasions, but the other died due to spinal cord compression after bisphosphonate and radiotherapy treatments. In past years, sirolimus was used for GSD in some cases, but its effectiveness is unknown. In this report, we describe the effectiveness and adverse effects of sirolimus for GSD as the basis for evaluating its therapeutic potential for this rare disease.

We report a case of a boy with GSD involving the clavicle and femur, who presented with pleural effusion as well as femoral fractures. Considering his age and side-effects of potential therapies, we gave him the mTOR (mammalian target of rapamycin) inhibitor sirolimus (rapamycin). Sirolimus is an immunosuppressant agent that directly targets mTOR. mTOR is a serine threonine kinase regulated by phosphoinositide 3 kinase (PI3K) and protein kinase B (Akt). The PI3K-Akt -mTOR signaling pathway is closely related to cell growth and proliferation and increases the expression of vascular endothelial growth factor (VEGF), regulating angiogenesis and lymphangiogenesis. mTOR inhibitors block downstream protein synthesis and have antitumor and anti-angiogenic effects. Sirolimus treatment was successful and the patient recovered completely. We describe the case to publicize the effect of sirolimus and provide an additional therapy for GSD. To date, 24 cases of GSD treated with sirolimus have been reported. All of the patients had bone lesions, and most of the patients were very responsive to sirolimus.

\section{Case presentation}

A 1 -year-old boy was born with a $2 \mathrm{~cm} \times 1.5 \mathrm{~cm}$ mass on the right side of his neck. He was admitted to a local hospital for treatment, and the neck CT showed cystic lesions on the superior and inferior aspects of the right clavicle, extending to the mediastinum. The local doctors gave a clinical diagnosis of suspected-lymphangioma according to radiological and clinical information.
However, treatment was not administered at that time. Over time, however, he presented shortness of breath owing to a right pleural effusion with the mass gradually enlarging to $4 \mathrm{~cm} \times 5 \mathrm{~cm}$ and came to the hospital. Physical examination showed that the mass was soft without specific boundaries, the skin was not red or swollen and there was no ulceration or fluid leakage. The chest wall behind the right clavicle collapsed with the clavicle absent causing the shoulder to droop. Respiratory sounds on the right side were faint whereas the left side was normal. The left femur was swollen and tender. The mobility of the right arm was slightly limited, and the patient found it difficult to walk. There was no significant shortness of the femur, and the arch mobility was normal. Furthermore, an X-ray showed partial osteolysis of the right clavicle with fracture of the left femur. X-rays also showed right pleural effusion with atelectasis on the right side (Fig. 1) A thoracoscopy was performed and the boy was given closed thoracic drainage via a pleural tube. After this surgery, the tumor shrank significantly. Following this, a femoral biopsy was performed that showed necrotic tissue in the cortical bone and many irregularly shaped capillaries that proliferated within the necrotic tissue. Dilated lymphatic vessels were seen adjacent to the cortex, with fibrous tissue hyperplasia (Fig. 2).

Based on these observations, the boy was diagnosed with Gorham Stout syndrome in November 2016. The boy was given sirolimus therapy (Hangzhou SinoAmerican East China Pharmaceutical Co. Ltd., $1 \mathrm{mg} / \mathrm{ml}$ ) simultaneously with SMZ (Shandong Xinhua Pharmaceutical Co. Ltd., $400 \mathrm{mg}$ Sulfamethoxazole \& $80 \mathrm{mg}$ Trimethoprim /piece) at an oral dose of $20-30 \mathrm{mg} / \mathrm{kg}$. Additionally, the patient received intramedullary fixation with bone grafting in the left femur. The dose of SMZ was divided in half and given twice a day, 3 days per

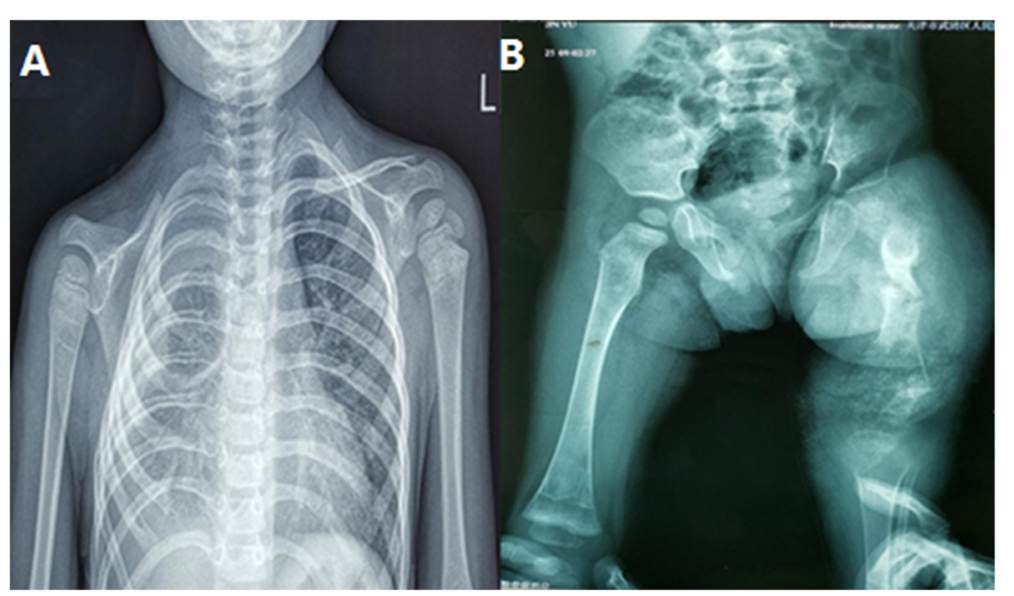

Fig. 1 (a) X-ray showing osteolysis in the right clavicle. A large pleural effusion was observed on the right-side, and the left lung was significantly compressed. (b) X-ray showing the fracture of the left femur 

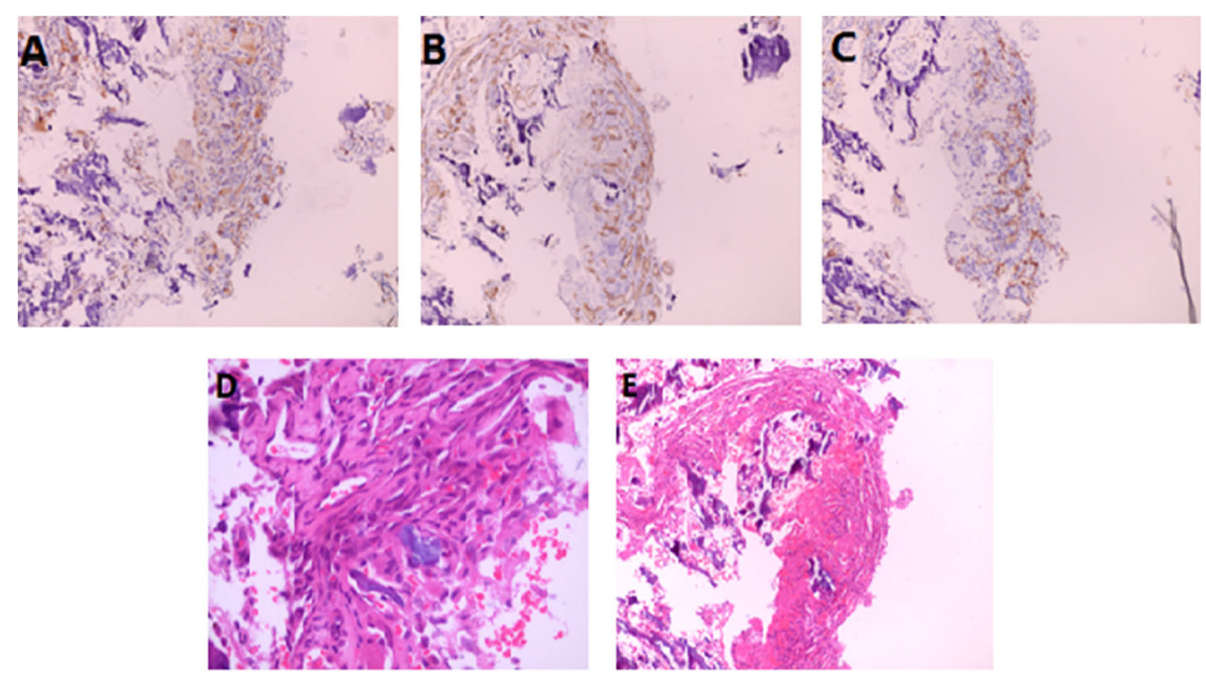

Fig. 2 (a) Immunopathological examination was positive for vessel marker CD31. (b) Immunopathological examination was positive for vessel marker CD34. (c) Immunohistochemical staining for D2-40, a specific lymphatic marker, was positive in the bone tissue biopsy. (d) Vessel and lymphatic proliferation within necrotic bone tissue (hematoxylin-eosin [HE], 100x magnification). (e) Vessel and lymphatic proliferation within necrotic bone tissue (hematoxylin-eosin [HE], 400x magnification)

week to prevent pneumocystis infection. Twenty-six months later, the boy had responded well to treatment. Physical examination showed that the mass had disappeared completely. Although the chest wall behind the right clavicle and shoulder were the same, respiratory sounds on the right side were more distinct than before. The left femur returned to nearly normal. X-rays showed that the pleural effusion was reduced significantly, there were no further lesions in the femur, and the thigh was no longer swollen (Fig. 3).

Fortunately, the boy did not experience any complications while taking sirolimus. At present he has recovered well and participated in normal daily activities. His growth and development are the same as that of his peers, and he has been minimally affected by the disease (Fig. 4) (figures were published authorized by the patient's family).

\section{Discussion and conclusion}

Lymphatic malformations (LMs) are benign vascular lesions caused by embryological abnormalities in the development of the lymphatic system [18]. In 2014, the International Society for the Study of Vascular Anomalies (ISSVA) updated the classification, which was approved at the 20th workshop (Fig. 5). Because clinical findings overlap, and disease etiology management, outcomes, and sequelae are unclear, intractable LMs (termed complex lymphatic anomalies, CLAs) are difficult to diagnose. Interestingly, osteolytic lesions are useful for distinguishing between general lymphatic anomalies (GLA)/Kaposiform lymphatic anomalies (KLA) and GSD. GSD is characterized by cortical resorption and progressive, often extensive, osteolysis, accompanied by adjacent soft tissue changes. In contrast, GLA involves organs such as lung,

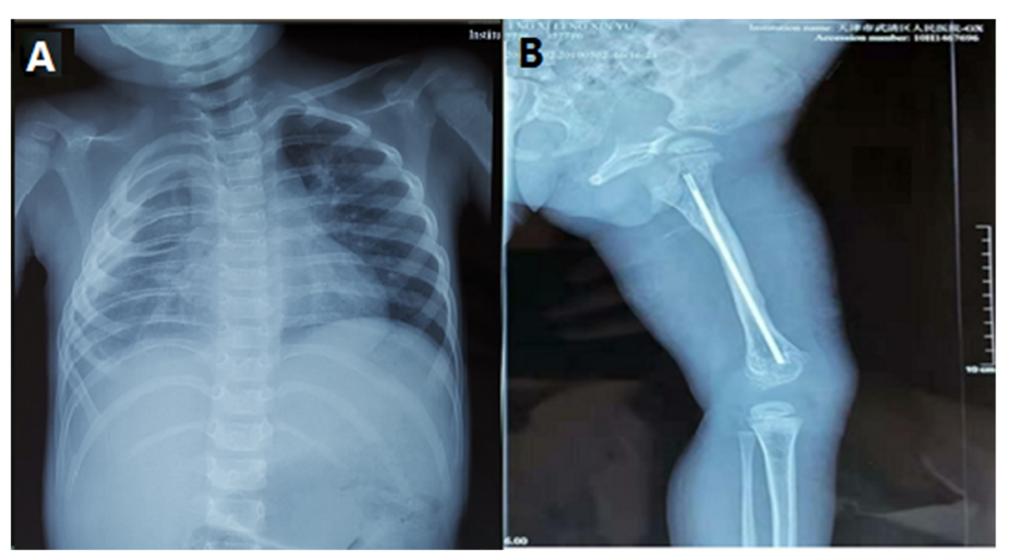

Fig. 3 (a) X-ray showing a little pleural effusion in the right thoracic cavity. (b) X-ray of the left femur showing that the bone is remodelling well 


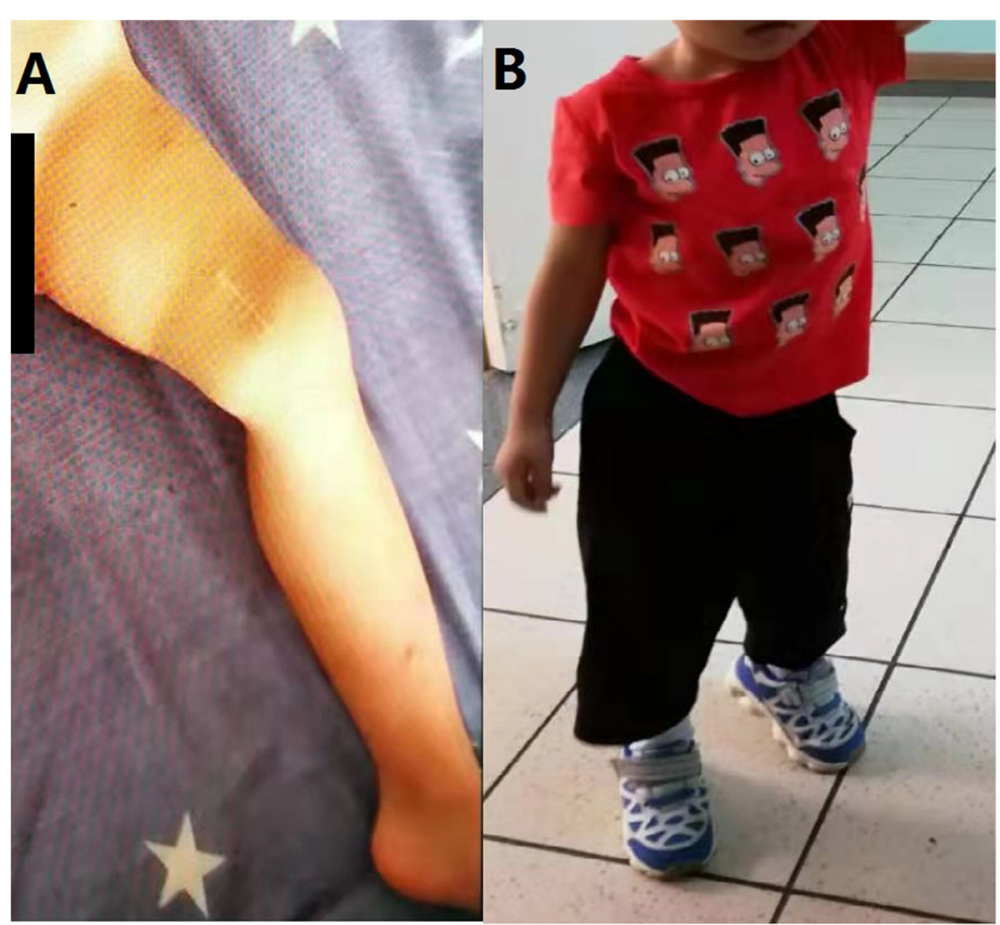

Fig. 4 (a) The left femur healed without deformity and swelling was absent. (b) The boy can walk normally and can perform activities of daily living without restriction

spleen and diffuse proliferating lymphatic vessels, with osteolysis confined to the medullary cavity and no cortical destruction. Particularly, patients with KLA have significant coagulation dysfunction with hemorrhagic pericardial and pleural effusion. The histological hallmark of KLA is a cluster of Kaposiform, spindle-shaped lymphatic endothelial cells and accumulation of hemosiderin [19].

Gorham-Stout Disease (GSD) is a rare disorder characterized by progressive osteolysis and proliferation of lymphatic and blood vessels [20]. The clinical presentation commonly involves pain and bone fractures. While

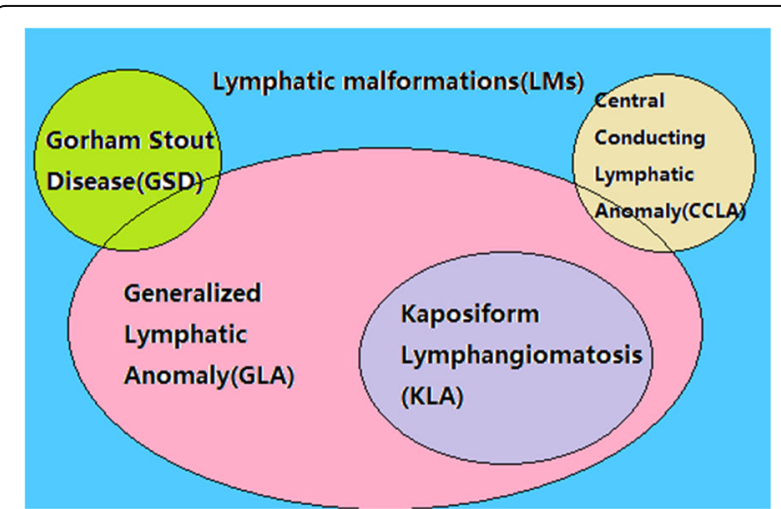

Fig. 5 ISSVA classification of lymphatic malformations. Complex lymphatic anomalies overlap their clinical symptoms and characteristics the mechanisms of osteolysis in GSD remain unclear, researchers have proposed a variety of hypotheses. As it is known that GSD osteolysis occurs adjacent to local proliferation of lymphatic vessels, the activation of osteoclasts and lymphangiogenesis is essential for the progress of GSD [21]; lymph is frequently seen in the osteolytic lesions. Franco-Barrera et al. [22] reported that the activation of the osteoclastogenic process that affects bone tissue is induced by immune mechanisms.

Due to the low incidence of GSD, current literature is confined to case reports and case series. To date, this is the largest analysis of the use of sirolimus therapy in patients with GSD. Sirolimus appears to stabilize or reduce signs/symptoms of disease and improve quality of life in these affected individuals. In 2011, an early report showed sirolimus was used for GSD with good results. A total of 16 patients including the present case and conference abstracts with detailed histories have been reported in the peer-reviewed literature (Table 1). In this report, patients were 1 to 43 years old, but $62.5 \%$ of them were children under the age of 14 . There was no sex difference in incidence, with 8 males and 8 females, consistent with previous reports of GSD cases. The clinical manifestations varied. Among them, nine patients had pleural effusion or chylothorax. These patients were subjected to more than one therapy, e.g., surgery or medication. Before administering sirolimus, zoledronic acid, interferon, or propranolol were given, indicating 


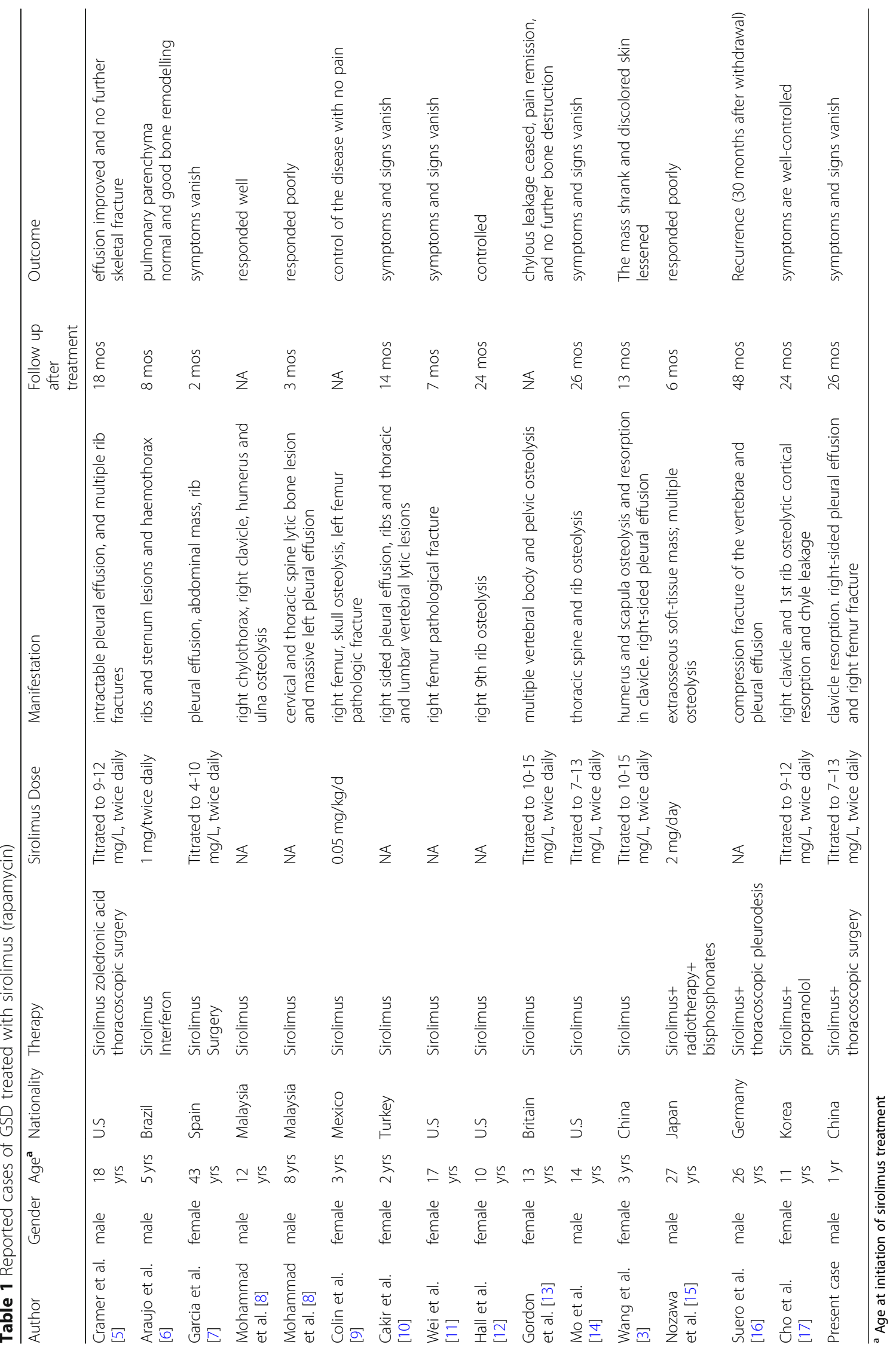


that the current therapeutic protocols are not uniform (Table 2). In addition to cases listed in Table 1, Ricci et al. [23] and Ozeki et al. [24] reported eight cases treated with sirolimus but did not provide clinical histories of these cases. Six of the eight cases responded well to sirolimus. Therefore, the overall positive response rate was $83.3 \%(20 / 24)$ of cases. Only one patient developed adverse effects of restrictive lung disease. He was given supportive care after stopping sirolimus treatment. These results show that sirolimus was well tolerated, even in neonates, without significant adverse effects.

The boy in this case was admitted to the hospital with a mass on the right side of his neck and neck pain. X-rays indicated partial osteolysis of the right clavicle. Normal bone tissue was replaced by proliferating non-neoplastic vascular tissue, like a hemangioma or lymphangioma. With the development of the disease the boy sustained a femoral fracture and developed pleural effusion. The diagnosis of GSD is extremely difficult, particularly in the early stage. Therefore, the diagnosis of GSD often is based on exclusion criteria (considering age, manifestation, radiology) and on the analysis of a bone biopsy. The understanding of molecular and cellular mechanisms leading to progressive osteolysis is inadequate.

Recently, some serum biomarkers have been highlighted as potentially diagnostic tools for GSD [20]. These include telopeptide of type I collagen (ICTP), Sclerostin, VEGF-A and IL-6. The sensitivity and specificity of these markers requires more clinical trials to verify their diagnostic utility. There is no standardized therapy for GSD. If surgery is not possible, radiotherapy or medication are alternative treatment modalities. Recently, several researchers have reported the mTOR inhibitor sirolimus can prevent lymphangiogenesis and

Table 2 Characteristics of reported cases $^{a}$

\begin{tabular}{lll}
\hline Characteristics & Present patient $(\mathrm{Y}=\mathrm{Yes} \mathrm{N}=\mathrm{No}$ ) & Reports (number) \\
\hline Symptoms and signs & & 15 \\
Osteolytic lesions & $\mathrm{Y}$ & 3 \\
Chylothorax & $\mathrm{N}$ & 1 \\
Abdominal mass & $\mathrm{N}$ & 5 \\
Pleural effusion & $\mathrm{Y}$ & \\
Gender & & 7 \\
Male & $\mathrm{Y}$ & 8 \\
Female & $\mathrm{N}$ & \\
Medical Therapy & & 2 \\
Bisphosphonate & $\mathrm{N}$ & 3 \\
Propranolol & $\mathrm{Y}$ & 15 \\
Sirolimus & $\mathrm{Y}$ & \\
Surgery & & 2 \\
Thorascopic & Y
\end{tabular}

${ }^{a}$ Based on the 16 studies in Table 1 decrease lymphatic endothelial cell activity [25] without adverse effects on normal lymphatics [26]. Because of the absence of evidence-based treatment guidelines, the dose and duration of sirolimus used in different studies varies significantly. In most studies, the initial dose was $0.8 \mathrm{mg} / \mathrm{m}^{2}$ of body surface area at 12 -h intervals, or twice daily, and the targeting concentration in blood was $5-15 \mathrm{ng} / \mathrm{ml}$ or $10-15 \mathrm{ng} / \mathrm{ml}$ [27]. The disease went into complete remission with decreased pleural effusion, reduced lymphatic leakage and the arrest of osteolytic progression. This may offer an additional therapy that Chinese physicians can use. However, the sample size is small, so further studies are needed to confirm the efficacy of sirolimus for GSD.

The patient had the disease, with involvement of the left clavicle and the right femur, when he was born. Later he developed right pleural effusion and dyspnea. Thoracoscopy and closed thoracic drainage were performed. At that point, a fracture of the left femur was identified, and the biopsy results suggested a diagnosis of GSD. The image of profound osteolysis of the left femur with nearcomplete resorption of the clavicle complicated by a rightsided pleural effusion, as well as pathology of the femur, indicated that the boy had Gorham-Stout disease. This is the second GSD case treated with sirolimus reported in China. It is also the first international review of the literature on sirolimus in the treatment of GSD and may provide guidance for the future application of sirolimus in the treatment of this disease.

GSD is a disease with an unclear pathogenetic mechanism and different potential clinical therapies. This report summarizes the clinical history, diagnosis and treatment of GSD in a patient, and reviews the recent literature on sirolimus as a treatment for GSD. In contrast to zoledronic acid and interferon, sirolimus is an oral preparation, which is convenient, improves compliance, and has fewer adverse effects. Because GSD usually occurs in children, radiotherapy can have a negative impact on the child's growth and development, so it should not be recommended as a first line treatment. Because of its safety and efficacy, fewer adverse effects, and convenience, sirolimus may become an alternative medication for the treatment of GSD, but a larger randomized controlled trial needs to be performed.

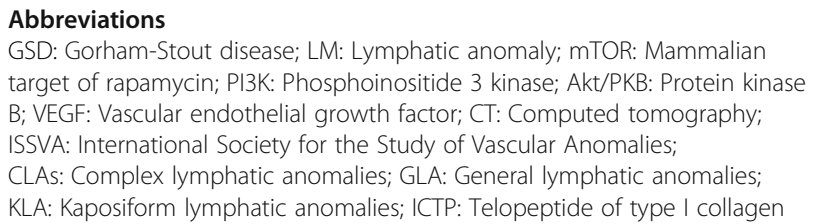

Acknowledgements

We thank Dr. Song Gu for sharing his expertise in treating patients with GSD and his selfless help. And we are grateful to professor Yeming Wu, Director of Pediatric Surgery, Xinhua Hospital affiliated to Shanghai Jiao Tong 
University School of Medicine, for his assistance in the work. All authors have contributed to the manuscript in significant ways and have reviewed and agreed upon the manuscript content. We thank Editsprings (www.edit. springs.com) for its linguistic assistance during the preparation of this manuscript.

\section{Authors' contributions}

All authors have read and approved the manuscript. YL proposed this idea and completed most of writing. RCT Participated in literature searching and writing. JW, YHS, HXG, CJX, MX and JJL spent a lot time screening and analyzing the literature and performing graphs. SG contributed the case and provided financial support.

\section{Funding}

This study was funded by the Shanghai Science and Technology Committee (17441903200, 17411950402); Science and Technology Development Fund of Shanghai Pudong New District (PKJ2017-Y04).

The funders provided sufficient funding for the study to collect cases and to organize and analyze data.

\section{Availability of data and materials}

All data generated or analysed during this study are included in this published article.

\section{Ethics approval and consent to participate}

This study was given approval by the Ethics Committee of Shanghai Children's Medical Centre (SCMCIRB-K2017004), and written informed consent was obtained from all participants. The parents of the patient have given their parental consent for this study.

\section{Consent for publication}

The written consent to publish this information was obtained from all participants, and the parents of the patient has given their parental consent for this study. This study was given approval by the Ethics Committee of Shanghai Children's Medical Centre (SCMCIRB-K2017004).

\section{Competing interests}

The authors declare that they have no competing interests.

Received: 4 April 2020 Accepted: 27 July 2020

Published online: 25 August 2020

\section{References}

1. Escande C, Schouman T, Francoise G, et al. Histological features and management of a mandibular Gorham disease: a case report and review of maxillofacial cases in the literature. Oral Surg Oral Med Oral Pathol Oral Radiol Endod. 2008;106(3):e30-7.

2. Gorham LW, Stout AP. Massive osteolysis (acute spontaneous absorption of bone, phantom bone, disappearing bone); its relation to hemangiomatosis. J Bone Joint Surg Am. 1955;37-A(5):985-1004.

3. Wang Z, Li K. A girl with Gorham-Stout disease. J Pediatr. 2018;203:456.

4. Tena-Sanabria ME, Jesus-Mejenes LY, Fuentes-Herrera G, Alvarez-Martinez FA, Victorio-Garcia NP, Nunez-Enriquez JC. A report of two children with Gorham-Stout disease. BMC Pediatr. 2019;19(1):206.

5. Cramer SL, Wei S, Merrow AC, Pressey JG. Gorham-Stout disease successfully treated with sirolimus and zoledronic acid therapy. J Pediat Hematol Onc. 2016;38(3):E129-32.

6. Araujo CA, Carvalho B, Carvalho I, et al. Management of Gorham-stout disease complicated by chylothorax, haemothorax and chylopericardium. Interact Cardiovasc Thorac Surg. 2017;25:163.

7. Garcia V, Alonso-Claudio G, Gomez-Hernandez MT, Chamorro AJ. Sirolimus on Gorham-Stout disease. Case report. Colomb Med (Cali). 2016;47(4):213-6.

8. Mohammad N, Che Daud CZ, Zainuddin H, Kassim A, Kunaseelan S. Gorham-stout disease-two case reports. Pediatr Pulmonol. 2019;54:S133.

9. Colin GM, McKinster CD, Romero MTG. Cutaneous lymphatic malformations in disappearing bone disease (Gorham stout). A case report. Pediatr Dermatol. 2017:34:S206-7.

10. Cakir FB, Khalif F, Ziyade S, Kutlu ON, Elmadag M. Gorham-stout syndrome with massive pleural effusion responsive to sirolimus. Pediatr Blood Cancer. 2016;63:S236.
11. Wei D, Wang T. Gorham-stout syndrome (vanishing bone disease): a case of a rare entity. Am J Clin Pathol. 2018;150:S25-6.

12. Hall NS, Carpenter SL. Gorham's disease: a case of vanishing ribs and its effective treatment with sirolimus. Blood. 2014;124(21).

13. Gordon KD, Mortimer PS. Progressive lymphangiomatosis and Gorham's disease: case report and clinical implications. Lymphat Res Biol. 2011;9(4): 201-4.

14. Mo AZ, Trenor CC 3rd, Hedequist DJ. Sirolimus therapy as perioperative treatment of Gorham-Stout disease in the thoracic spine: a case report. JBJS Case Connect. 2018;8(3):e70.

15. Nozawa A, Ozeki M, Hori T, Kato H, Ohe N, Fukao T. Fatal progression of Gorham-Stout disease with skull base osteomyelitis and lateral medullary syndrome. Intern Med. 2019;58(13):1929-33.

16. Suero Molina EJ, Niederstadt T, Ruland V, et al. Cerebrospinal fluid leakage in Gorham-Stout disease due to dura mater involvement after progression of an osteolytic lesion in the thoracic spine. J Neurosurg Spine. 2014;21(6) 956-60.

17. Cho S, Kang SR, Lee BH, Choi S. Chylous manifestations and management of Gorham-Stout syndrome. Korean J Thorac Cardiovasc Surg. 2019;52(1):44-

18. Elluru RG, Balakrishnan K, Padua HM. Lymphatic malformations: diagnosis and management. Semin Pediatr Surg. 2014:23(4):178-85.

19. Ozeki M, Fukao T. Generalized lymphatic anomaly and Gorham-Stout disease: overview and recent insights. Adv Wound Care (New Rochelle). 2019;8(6):230-45.

20. Rossi M, Buonuomo PS, Battafarano G, et al. Dissecting the mechanisms of bone loss in Gorham-Stout disease. Bone. 2020;130:115068. https://doi.org/ 10.1016/j.bone.2019.115068.

21. Hagendoorn J, Yock TI, Borel Rinkes IH, Padera TP, Ebb DH. Novel molecular pathways in Gorham disease: implications for treatment. Pediatr Blood Cancer. 2014;61(3):401-6.

22. Franco-Barrera MJ, Zavala-Cerna MG, Aguilar-Portillo G, et al. Gorham-Stout disease: a clinical case report and immunological mechanisms in bone erosion. Clin Rev Allergy Immunol. 2017;52(1):125-32.

23. Ricci KW, Hammill AM, Mobberley-Schuman P, et al. Efficacy of systemic sirolimus in the treatment of generalized lymphatic anomaly and GorhamStout disease. Pediatr Blood Cancer. 2019:66(5):e27614

24. Ozeki M, Asada R, Saito AM, et al. Efficacy and safety of sirolimus treatment for intractable lymphatic anomalies: a study protocol for an open-label, single-arm, multicenter, prospective study (SILA). Regen Ther. 2019;10:84-91.

25. Adams DM, Trenor CC 3rd, Hammill AM, et al. Efficacy and safety of Sirolimus in the treatment of complicated vascular anomalies. Pediatrics. 2016;137(2):e20153257

26. Baluk P, Yao LC, Flores JC, Choi D, Hong YK, McDonald DM. Rapamycin reversal of VEGF-C-driven lymphatic anomalies in the respiratory tract. JCI Insight. 2017:2(16):e90103.

27. Triana P, Dore M, Cerezo VN, et al. Sirolimus in the treatment of vascular anomalies. Eur J Pediatr Surg. 2017;27(1):86-90.

\section{Publisher's Note}

Springer Nature remains neutral with regard to jurisdictional claims in published maps and institutional affiliations.

Ready to submit your research? Choose BMC and benefit from:

- fast, convenient online submission

- thorough peer review by experienced researchers in your field

- rapid publication on acceptance

- support for research data, including large and complex data types

- gold Open Access which fosters wider collaboration and increased citations

- maximum visibility for your research: over $100 \mathrm{M}$ website views per year

At $\mathrm{BMC}$, research is always in progress.

Learn more biomedcentral.com/submissions 